\title{
Evaluation of NeuroPage as a memory aid for people with Multiple Sclerosis: A randomised controlled trial
}

Rachel A Goodwin ${ }^{\text {ab }}$, Nadina B Lincoln ${ }^{\mathrm{a}}$, Roshan das Nair ${ }^{\mathrm{ac}} \&$ Andrew

Bateman $^{\mathrm{b}}$

${ }^{a}$ Division of Rehabilitation \& Ageing, University of Nottingham, Nottingham, UK

${ }^{b}$ The Oliver Zangwill Centre for Neuropsychological Rehabilitation, Ely, UK

${ }^{c}$ Division of Psychiatry \& Applied Psychology, Institute of Mental Health, School of Medicine, University of Nottingham, UK

Correspondence should be addressed to Rachel Goodwin, The Oliver Zangwill Centre, Princess of Wales Hospital, Ely, CB6 1DN. Telephone: 01353 652165, Email:

Rachel.goodwin@nhs.net, Orcid ID: 0000-0002-4084-3120. 


\title{
Evaluation of NeuroPage as a memory aid for people with Multiple Sclerosis: A randomised controlled trial
}

\author{
Memory problems are reported in 40-60\% of people with multiple sclerosis \\ (MS). These problems affect independence and may limit the ability to benefit \\ from rehabilitation. Our aim was to evaluate the effectiveness of NeuroPage for \\ people with MS living in the community. A multicentre, single-blind randomised \\ controlled crossover trial was conducted. The intervention comprised the \\ NeuroPage service, which sends reminder messages to mobile phones at pre- \\ arranged times. In the control condition participants received "non-memory \\ texts", that is messages not aimed at providing a reminder, for example supplying \\ News headlines or sport updates. Outcome measures were completed using postal \\ questionnaires after each condition. There were 38 participants, aged 28 to 72 \\ (mean 48, S.D. 11) and 10 (26\%) were men. There were no significant \\ differences between NeuroPage and control conditions on the Everyday Memory \\ Questionnaire ( $\mathrm{p}=0.41, \mathrm{~d}=0.02$ ). The number of daily diary items forgotten in the \\ NeuroPage condition was significantly less than in the control (9\% vs. 31\%, \\ $\mathrm{p}=0.01, \mathrm{~d}=-0.64)$. Psychological distress was less in the NeuroPage condition \\ than control $(\mathrm{p}=0.001, \mathrm{~d}=-0.84)$. Further evaluation of the effect on everyday \\ memory is required.
}

Keywords: multiple sclerosis, memory, neuropsychological rehabilitation, memory aid, RCT

\section{Introduction}

Approximately $40-60 \%$ of people with multiple sclerosis (MS) have memory problems (Rosti-Otajärvi \& Hämäläinen, 2014). Many report feeling more restricted by cognitive impairments than by limited mobility (Amato, Zipoli, \& Portaccio, 2006), and their quality of life is decreased (Grima et al., 2000). Cognitive impairment in people with MS is often a hidden condition, which brings difficulties in everyday functioning, and 
contributes to depression, anxiety, distress and fatigue (Gilchrist \& Creed, 1994; Sá, 2008). Cognitive impairments may interfere with daily functioning (Engel, Greim, \& Zettl, 2007), participation in social activities (Thomas, Thomas, Hillier, Galvin \& Baker, 2006) and employment status (O'Brien, Chiaravalloti, Goverover, \& DeLuca, 2008; Rao et al., 1991). Memory is one of the most commonly affected of cognitive functions in people with MS (Benedict et al., 2006) and the most often reported to affect daily life (Samartzis, Gavala, Zoukos, Aspiotis \& Thomaides, 2014).

There are two main approaches to memory rehabilitation: restitution and compensation (Evans, 2006; Sohlberg \& Mateer, 1989). Restitution involves repeated practice on tasks that involve the impaired function. Compensatory approaches include training in internal memory aids, such as mnemonics; environmental modification; and the use of external aids. The most commonly used strategy is the use of external aids to reduce the cognitive load and enable successful completion of a task (Linden et al., 2016). External memory aids do not aim to improve memory, but focus on reducing functional problems, by means of recording and accessing information externally (Teasell et al., 2007). However, the process of learning to use an external memory aid is not straightforward and some people require support to use them (Evans, 2004).

There are many external memory aids, such as smartphones, voice recorders, watches with alarms and paging devices (Dewar, Kopelman, Kapur, \& Wilson, 2014). They can be used to hold information concerning target behaviours, such as a reminder to take medication. Additionally, the content of a reminder may provide monitoring information, such as medication needs to be refilled, or output monitoring, such as, “have you refilled your medication?" People with memory problems may have difficulty in developing rehabilitation strategies, because they forget to apply compensatory techniques that they have been taught. Technological aids may counteract 
this problem, as users do not have to remember to use the device (Lannin et al., 2014; Wilson, Evans, Emslie \& Malinek, 1997). Johnson, Bamer, Yorkston, and Amtmann (2009) surveyed over 1,000 people with MS and found that approximately half of them used electronic memory aids.

Much of the neuropsychological rehabilitation literature on electronic memory aids has focussed on NeuroPage, an alpha-numeric paging system that provides audio/vibration alerts and is suitable for those with a wide range of memory and other cognitive problems (Wilson, Emslie, Quirk, \& Evans, 2001; Wilson, Emslie, Quirk, Evans, \& Watson, 2005; Hersh \& Treadgold, 1994). It sends Short Message Service (SMS) text messages to mobile phones or pagers, and is widely available. Reminders are externally programmed, and therefore NeuroPage requires only limited training or learning by the patient to be used effectively (Kapur, Glisky, \& Wilson, 2004). NeuroPage assists people with memory and planning problems following acquired brain injury, in achieving everyday target behaviours, relative to baseline (Fish, Manly, Emslie, Evans \& Wilson, 2008; Wilson et al., 2005; Wilson et al., 2001).

Mobile phones and smartphones are ubiquitous in the general population, and are portable, socially acceptable and cost-effective (Dewar et al., 2014). Smartphone technology has created a Personal Digital Assistant (PDA)-style memory aid within our mobile phones, including functions that remind you to perform a specific task when you arrive at a certain location. However, people with moderate-severe cognitive impairments still need to be trained to use them as an effective memory aid (Svoboda, Richards, Leach, \& Mertens, 2012).

The effectiveness of memory rehabilitation programmes for people with MS is far from conclusive (Carr, das Nair, Schwartz, \& Lincoln, 2014). A Cochrane review (das Nair, Martin, \& Lincoln, 2016) evaluated the evidence for effectiveness of memory 
rehabilitation for people with MS, and concluded that there was some evidence to support the effectiveness of memory rehabilitation for people with MS. Those who had memory rehabilitation had better memory functioning compared to those who did not receive memory rehabilitation. However, this was based on few studies, many with methodological limitations. Furthermore, another systematic review by Goodwin, Lincoln, das Nair and Bateman (2017) evaluating the use of external memory aids for people with MS, concluded there was insufficient evidence to support or refute the effectiveness of external aids for improving memory function in people with MS. Therefore there is some suggestion that compensatory strategies, such as memory aids, could be effective in reducing everyday memory problems in people with MS but further evidence is required.

There is evidence for the effectiveness of Neuropage (Fish et al., 2008; Wilson, Emslie, Quirk \& Evans, 1999; Wilson et al., 2005; Wilson et al., 2001, Wilson et al., 1997), but this is mainly from participants with stroke or traumatic brain injury. Although smart phones and mobile phones are used as external memory aids, there has been little effort to assess their usefulness (Baddeley, Eysenck \& Anderson, 2014). A review of NeuroPage, (Martin-Saez, Deakins, Winson, Watson \& Wilson, 2011) concluded that the service continued to have a role within cognitive rehabilitation. Therefore, this study evaluated the effectiveness of NeuroPage for people with MS. The aim was to evaluate whether people with MS who used NeuroPage memory text messages showed reduced frequency of memory problems in daily life, increased attainment of personally identified goals, reduced distress and improved quality of life, compared with those who received social text messages, as a control condition. 


\section{Methods}

\section{Design}

This was a single-blind, crossover randomised controlled trial (RCT) comparing NeuroPage with a control condition comprising social text messages. Treatment efficacy was determined by comparing performance on outcome measures completed at the end of each condition. No comparison with baseline performance was conducted in order to reduce the risk of a false positive result (Bland \& Altman, 2011).

\section{Participants}

Participants were recruited from five UK NHS Trusts and through an MS charity event. Participants were included if they:

(1) had been diagnosed with MS more than 12 months before joining the study

(2) had self-reported memory problems, defined as a score more than 20 on the selfreport version the Everyday Memory Questionnaire (EMQ; Sunderland, Harris $\&$ Gleave, 1984). This cut-off represents the $25^{\text {th }}$ percentile of a sample of people who took part in a memory rehabilitation study (das Nair \& Lincoln, 2012) and therefore comprised those with moderate and severe memory problems in daily life

(3) were aged 18 years or older

(4) gave informed consent

Participants were excluded if they: 
(1) had cognitive, visual or motor impairment, such that they were unable to use a pager or mobile phone

(2) had another concurrent neurological diagnosis, e.g. epilepsy

(3) had a concurrent severe medical or psychiatric diagnosis

(4) were concurrently taking part in other psychological intervention studies

(5) did not understand English

\section{Procedure}

At the baseline assessment participants were offered the choice of receiving text messages to a pager or mobile phone. Participants and their relatives or carers were asked to describe a typical week to elicit problems that they needed help with (e.g., "I forget to lock the back door" or "I forget to take my medication") and to identify target behaviours they wanted to achieve (e.g., "I want to remember to take my medication every day"). Participants then agreed on reminders that would be helpful to achieve these target behaviours. They were shown a list of common reminders to see whether they thought any of them would be useful. Participants also identified the type of nonmemory messages they would be happy to receive (e.g., sports news and current affairs).

Self-reported demographic information and details of type of MS and years since diagnosis were recorded. A cognitive assessment was conducted to document the nature of the memory impairment and to record factors that may be related to treatment response. The measures used were:

- Everyday Memory Questionnaire (EMQ)(Sunderland, Harris, \& Baddeley, 1983) to assess memory functioning in everyday life. The EMQ consists of 28 items, each describing everyday activities, which may involve memory failure, 
and each item is rated on the frequency of occurrence. Scores range from 0 to 112, with higher scores suggesting more frequent forgetting.

- Doors and People Test (Baddeley, Emslie \& Nimmo-Smith, 1994) to assess memory performance. This battery of four tests yields a single age-scaled overall score which is derived from individual measures of visual and verbal memory, recall and recognition and forgetting (Evans, Wilson, \& Emslie, 1996). Scaled scores range from 0 to 19 , with lower scores suggesting more impaired memory performance, and average performance indicated by a score of 10 .

- Hayling and Brixton tests (Burgess \& Shallice, 1997) to assess executive functions. The Hayling Test evaluates initiation speed and response suppression, and the Brixton Test is a rule detection and rule following task. Sten scores range from 1 to 10 with a standard deviation of 2 , with lower scores suggesting more impaired executive functioning performance, and average performance indicated by a score of 5 .

- Test of Everyday Attention (TEA; Robertson, Ward, Ridgeway, \& NimmoSmith, 1994) is a battery of eight tasks to measure attentional processes. Agescaled scores were derived for each subtest. As with the Doors and People test, scores range from 0 to 19 , with lower scores suggesting more impaired attention performance.

Participants were randomly allocated to the intervention or the control group on a 1:1 ratio. Allocation was determined by an independent research assistant, using a randomisation sequence prepared in advance of the study, The independent research assistant disclosed the group allocation of the participant to the researcher delivering the intervention only after the allocation was recorded. Due to the nature of the intervention, both the treating researcher and participants were aware of which group 
they had been allocated to.

Prior to the first condition, the researcher explained the messaging system and checked that participants knew how to open new SMS messages on their mobile phones. Those who wished to receive the messages to a pager rather than their mobile phone were given a demonstration.

\section{Interventions}

During the intervention phase, participants received NeuroPage text messages for two months sent from a computer based at the Oliver Zangwill Centre for Neuropsychological Rehabilitation (OZC) in Ely, UK. NeuroPage messages were based on the problems identified at baseline and prompts sent at pre-arranged times. Only messages requested or agreed by participants were selected for transmission. Participants also chose the wording of the messages and were free to modify these as necessary during the trial. An example is shown in Figure 1. Two days after the start of the intervention, participants were contacted by text message to check that the NeuroPage messages were being received.

Figure 1 about here

During the control phase, participants received non-memory text messages for two months. Participants were free to modify these during the trial. We explained that the non-memory messages would be transmitted at the same times and frequency as the NeuroPage messages, unless requested otherwise. An example is shown in Figure 2. 
Two days after the start of the control condition, participants were contacted by text message to check the control messages were being received.

Figure 2 about here

Any other rehabilitation, e.g. occupational therapy or physiotherapy, continued as usual for all participants. Any medication, including MS disease modifying drugs and anti-depressants continued as usual for all participants.

\section{Outcomes}

Outcomes were assessed at the end of each condition. Questionnaires were posted to participants two days prior to the end of the condition, with a pre-paid addressed return envelope. Three weeks were allowed for completion between conditions. Participants were sent a text reminder two weeks after each condition ended if the completed questionnaires had not been received. If participants reported that they were unable to complete the questionnaires, they were asked to complete the EMQ over the phone.

The primary outcome measure was the Everyday Memory Questionnaire (EMQ) 28 self-report version. The EMQ has been employed in previous studies evaluating memory rehabilitation for people with MS (Carr et al., 2014; das Nair \& Lincoln, 2012; Lincoln et al., 2002).

Secondary outcomes were assessed on the following questionnaires.

- Everyday Memory Questionnaire 28 informant-report version. 
- General Health Questionnaire 30 (GHQ)(Goldberg \& Williams, 1988) to assess psychological distress. This measures common mental health problems, including depression, anxiety, somatic symptoms and social withdrawal. Scores range from 0 to 90, with a higher total score on GHQ indicating more reported distress.

- EQ-5D was used to assess health status (The EuroQol Group, 1990). It has five dimensions (mobility, self-care, usual activities, pain/discomfort and anxiety/depression) which are each rated at three levels: no problem, some problems, extreme problems. Scores range from 1 to 3, with a higher score on each item indicating a poorer quality of life. A visual analogue scale gives an overall rating of quality of life on a scale from 0 to 100 .

- Adaptation to Memory Difficulties Outcome questionnaire (AMEDO)(Chouliara \& Lincoln, 2015) was used to assess coping with memory problems. Part A comprises questions about how participants cope with their memory problems, ranked on a 4-point Likert scale; Part B includes checklists of memory aids used, and questions on how participants use them. Scores range from 15 to 60 in part $\mathrm{A}$ and from 4 to 16 in part $\mathrm{B}$, with a lower score on AMEDO indicating poorer coping strategies for memory problems; and poorer use of external and internal aids respectively.

- The daily diary, completed in the final two weeks of each condition, was used as a self-defined outcome measure relating to participants' everyday memory problems. Participants recorded the frequency of forgetting the tasks they received reminders for. The daily diary has been used in previous studies evaluating NeuroPage (Fish et al., 2008; Wilson et al., 2001; Wilson et al., 
1997). Scores range from 0 to $100 \%$, with higher scores indicating more frequent forgetting.

Outcome measures were scored and entered into a password protected database by a researcher blind to group allocation.

\section{Statistical methods}

Statistical analyses were carried out using IBM SPSS Statistics version 22.0. Intention-to-treat analysis was used.

Paired analysis was used, as recommended for crossover trials (Elbourne et al., 2002). For all outcome measures, scores from both groups were combined to get a dataset for performance after the NeuroPage condition and after the control condition. A paired t-test (Higgins \& Green, 2013) was used to compare performance after the NeuroPage and control conditions. Bonferroni adjustments were not performed based on the view that they are "unnecessary" and increase the likelihood of type II errors, so that truly important differences are deemed non-significant (Armstrong, 2014; Perneger, 1998).

Effect sizes were estimated using Cohen's d (Cohen, 1988; Field, 2013), and were classified as: 0.2 small, 0.5 moderate, 0.8 large.

Ethical approval was granted by the National Research Ethics Committee - East Midlands (Northampton, reference 13/EM/0324). Research and Development approvals were also granted by the National Health Service (NHS) Trusts which were our recruiting sites.

\section{Results}




\section{Recruitment}

Of the 107 people referred to the trial, 103 were assessed for eligibility and 4 could not be contacted. Of the 103 assessed, 55 were excluded: 8 people did not score above the cut-off on the EMQ, 4 were unable to use a pager or phone, 41 did not want to take part, and 2 could not be contacted. Ten participants did not receive the messages as planned at the beginning of the trial and therefore the trial was restarted. Figure 3 shows the flow of participants through the trial.

Figure 3 about here

Outcomes analysis was conducted on 38 participants who were randomised after problems were rectified. Seventeen participants were randomised into group 1 and received NeuroPage then control, and 21 were randomised to group 2 and received control then NeuroPage. The demographic characteristics of the participants are shown in Table 1.

Table 1 about here

\section{Baseline data}

The distribution of scores on baseline measures is shown in Table 2.

Table 2 about here

\section{Outcomes}


The demographic characteristics and cognitive test performance of the groups were comparable at baseline. Scores on the Doors \& People subtests were mainly in the low to below average memory ability range. Performance on the Hayling \& Brixton tests showed mainly below average executive functioning. Overall scores on the Test of Everyday Attention were mainly below to low-average.

No participants dropped out from the intervention phase. One participant withdrew part way through the control condition.

A total of 885 reminder messages were requested in the NeuroPage condition and 788 in the control condition. The frequency and type of reminders are shown in Table 3. Messages regarding medication were the most commonly requested reminder in the NeuroPage condition. Messages requesting current affairs headlines were the most frequently requested in the control condition. One participant opted to receive messages to a pager and 37 participants chose to receive messages to their mobile phones.

Table 3 about here

The comparison of the two conditions is shown in Table 4.

Table 4 about here

There were significant differences between intervention and control conditions on the GHQ30, EQ5D anxiety/depression scale and the daily diary. Participants had less psychological distress and a lower frequency of forgetting everyday target behaviours while receiving NeuroPage compared to the control condition. There were 
no significant differences between NeuroPage and control conditions in the frequency of everyday memory problems, as rated by participants or informants, adaptation to memory difficulties or quality of life scales (mobility, self-care, usual activities and pain/discomfort). A large effect size was found for the GHQ30, and moderate effect size for the daily diary.

\section{Discussion}

Overall the study showed that receiving memory-related text messages had no effect on the self-reported overall frequency of memory problems in daily life, however there was a suggestion of beneficial effects on distress and the attainment of personal target behaviours. The lack of significant difference between conditions on the EMQ, suggests that the content of the messages may not affect the overall frequency of everyday memory problems.

However, we found that there was a moderate effect size and significant difference between conditions on the daily diary, demonstrating that participants showed better attainment of target behaviour when receiving NeuroPage messages, compared to the control condition. This discrepancy suggests that NeuroPage helped participants compensate for memory problems on the discrete recall of specific tasks, rather than in general, and suggests the content of the message was important in helping participants remember.

The EMQ assesses the overall frequency of everyday memory problems, and may not detect changes which are confined to prospective memory functioning. In future studies, it would be useful to include a measure of prospective memory, such as the Prospective and Retrospective Memory Questionnaire (PRMQ; Smith, Della Sala, 
Logie \& Maylor, 2000). These findings are consistent with three previous studies evaluating memory rehabilitation for people with MS, where no significant effect of treatment was detected on the EMQ (Carr et al., 2014; das Nair \& Lincoln, 2012; Lincoln et al., 2002). However, there was no appropriate alternative measure of everyday memory available that has been shown to be responsive to the effects of memory rehabilitation.

A large effect size and significant difference between conditions was found on the GHQ, where participants reported fewer symptoms of psychological distress while receiving NeuroPage than when receiving control messages. These findings were supported by a significant difference on the anxiety and depression question on the EQ5D. Another study by Carr et al. (2014) found that attending a group memory rehabilitation significantly improved mood in people with MS compared to usual care. Therefore, one explanation might be that receiving the reminder messages may have reduced participants' distress because they were remembering to do the things they needed to do, and so their everyday life was easier. However, it is also possible that the control condition increased distress and therefore further research is necessary to establish how the two conditions impacted on the reported levels of distress.

No differences between conditions were found on AMEDO, a scale that was developed as an outcome measure for memory rehabilitation. This may be because the AMEDO may be more appropriate for detecting effects of a comprehensive rehabilitation programme that aims to educate and train a variety of memory strategies. NeuroPage only aimed to support specific prospective memory problems, and so participants were unlikely to endorse questions such as "I understand how memory works" or "I have a range of internal memory aids that I can use for different tasks". 
The cross-over design allowed the comparison of the intervention to an active control, with randomisation, allocation concealment and blinding, to eliminate bias. However, although a washout period of three weeks was used to reduce carryover between conditions, some carryover may have occurred. A parallel arm RCT would have resolved this problem. However, one benefit of crossover trials is that participants experience both conditions, and can therefore express a preference for or against the treatments. Another benefit is that because each patient receives both conditions, crossover trials usually require half the number of participants to produce the same precision as a parallel group trial (Elbourne et al., 2002).

Due to the "home-based" nature of the intervention, adherence remains unknown. A literature review on the non-use of assistive technology devices reported high rates of non-adherence (Wessels, Dijcks, Soede, Gelderblom, \& De Witte, 2003). Therefore, some reminder messages may not have been read, and mobile phones may have been switched off or on silent mode. These events may also have occurred in the control condition and therefore been counterbalanced. However, future studies using more modern technologies may be able to detect when and how frequently information was accessed.

The EMQ and AMEDO were chosen on the basis of being self-report measures of cognitive problem in daily life. However subjective measures rely on participants' ability to report recent or current status, which require intact meta-memory skills, and these may be impaired in people with MS (Beatty \& Monson, 1991). People with worse memories may be worse at recalling memory failures and give themselves low frequency ratings (Sunderland et al.,1983). However, the self-report results on the EMQ were consistent with the informants' EMQ reports suggesting this is unlikely to have affected results (Goodwin, 2016). 
The outcome questionnaires were selected as being well-established for the evaluation of memory rehabilitation, and having good psychometric properties. Therefore, findings from this study are likely to be included in future meta-analyses. However, the EMQ probably is not sensitive to change in the achievement of target behaviours, and changes would not be expected on many items with this intervention, e.g. recognising faces. Changes important to the individual are often lost on global measures, and improvements too small to be statistically significant may still be important to the patient (Hanssen, Šaltytė Benth, Beiske, Landrø, \& Hessen, 2015; Khan, Pallant, \& Turner-Stokes, 2008).

Some participants did not return the outcome questionnaires. It is possible that those with the worst memories were under-represented as they forgot to return the outcome questionnaires. However, this would be expected in both conditions, and so would not affect the comparison. A few participants reported that they did not return questionnaires because of low mood. Face to face outcome assessment visits may be better in future studies to increase the compliance with follow-up assessments, but this may risk assessors becoming unblinded during assessments.

The decision not to compare outcome to baseline measure performance was made to reduce the likelihood of producing false positive results, however including this comparison could have helped better understand the nature of behaviour changes over the course of the trial. A potential limitation of the analyses was that multiple t-tests were performed, and interpreted without using the Bonferroni correction, and hence there is an increased likelihood that any significant differences are due to chance. Intention-to-treat analysis was used, where all data were categorised as the condition to which the participant was allocated. However, it was not possible to check adherence to the intervention. 
The t-tests only included participants' full data sets which reduced the sample size. No imputation of missing values was carried out, and therefore sensitivity analyses were not performed. As a result the study may have been underpowered to detect differences between conditions. A post hoc sample size calculation (Goodwin, 2016) for a definitive trial indicated a sample size 119 would have $80 \%$ power to detect a difference on the GHQ with an alpha of 5\% and allowing for 10\% dropout between baseline and follow-up. The sample size estimate for the daily diary as an outcome was 37 participants. These estimates indicate that a full powered trial is achievable. The decision to use these measures for the calculations was made in light of the issues found with the EMQ in this study, and the recommendations to use a different measure in future studies.

Everyday memory improvements were reported on the daily diary, but not on the EMQ or AMEDO. These results partially support the recommendations of Cicerone and colleagues (2011) and de Joode, van Heugten, Verhey, and van Boxtel (2010), to offer compensatory aids to people with memory problems; and Jamieson, Cullen, McGee-Lennon, Brewster and Evans' (2014) conclusion that there is evidence of benefits of prospective memory prompting devices for people with degenerative conditions. Therefore, there is some suggestion that people with MS can be supported by electronic memory aids to improve the achievement of target behaviours and improve mood.

Previous studies on NeuroPage have compared the intervention to usual-care (Wilson et al., 2001; Wilson et al., 2005; Wilson et al., 1997). This study used an active control, containing non-reminder content, which has allowed more exploration of the 
active ingredient of the intervention, e.g. the content or the prompting alert. Generally, participants had low to below average retrospective memory functioning, as shown by baseline assessments, and would not be expected to remember the target behaviour without receiving the reminder content. This was found in some participants who lost the benefit of NeuroPage when the condition finished. However, many participants reported a maintained benefit of NeuroPage into the control condition, which is suggestive of intact retrospective memory as they could remember the target behaviour. For this subset of participants a prompt was sufficient to trigger recollection of the content and perform the target behaviour. These findings mirror those of Fish and colleagues (2008) and suggest the most important element of NeuroPage, i.e. content or prompt, may be dependent on the nature of user's individual specific memory impairments.

There was no evidence to suggest that NeuroPage reduced the frequency of memory problems in daily life, or improved quality of life. However, there was evidence that those who received NeuroPage had better attainment of target behaviours and mood compared to control. Comparing NeuroPage with an active control showed that the content of the reminder messages appears to be important to the effectiveness of NeuroPage.

\section{Acknowledgements}

This work was supported by the MS Society under award reference number 971/12 and by the National Institute for Health Research East of England Collaboration for Leadership in Applied Health Research \& Care (NIHR CLAHRC EoE).

NeuroPage is offered from the Oliver Zangwill Centre as an NHS or privately funded treatment options but the authors do not receive any financial reward related to subscriptions to this service. 
This study was completed as partial fulfilment of a $\mathrm{PhD}$ conducted at the University of Nottingham.

\section{References}

Amato, M. P., Zipoli, V., \& Portaccio, E. (2006). Multiple sclerosis-related cognitive changes: a review of cross-sectional and longitudinal studies. Journal of the Neurological Sciences, 245(1), 41-46.

Armstrong, R. A. (2014). When to use the Bonferroni correction. Ophthalmic and Physiological Optics, 34(5), 502-508.

Baddeley, A. D., Emslie, H., \& Nimmo-Smith, I. (1994). Doors and people: a test of visual and verbal recall and recognition. Bury St. Edmunds: Thames Valley Test Company.

Baddeley, A. D., Eysenck, M., \& Anderson, A. (2014). Memory (2nd edn). Abingdon: Psychology Press.

Beatty, W. W., \& Monson, N. (1991). Metamemory in multiple sclerosis. Journal of Clinical and Experimental Neuropsychology, 13(2), 309-327.

Benedict, R. H., Cookfair, D., Gavett, R., Gunther, M., Munschauer, F., Garg, N., \& Weinstock-Guttman, B. (2006). Validity of the minimal assessment of cognitive function in multiple sclerosis (MACFIMS). Journal of the International Neuropsychological Society, 12(4), 549-558.

Bland, J. M., \& Altman, D. G. (2011). Comparisons within randomised groups can be very misleading. $B M J, 342, \mathrm{~d} 561$.

Burgess, P. W., \& Shallice, T. (1997). The Hayling and Brixton tests. Bury St. Edmunds: Thames Valley Test Company.

Carr, S. E., das Nair, R., Schwartz, A. F., \& Lincoln, N. B. (2014). Group memory rehabilitation for people with multiple sclerosis: a feasibility randomized controlled trial. Clinical Rehabilitation, 28(6), 552-561

Chouliara, N., \& Lincoln, N. B. (2015). Developing a questionnaire to assess the outcome of memory rehabilitation for people with neurological disabilities. International Journal of Therapy \& Rehabilitation, 22(10), 470-477.

Cicerone, K. D., Langenbahn, D. M., Braden, C., Malec, J. F., Kalmar, K., Fraas, M., . . . Bergquist, T. (2011). Evidence-based cognitive rehabilitation: updated review 
of the literature from 2003 through 2008. Archives of Physical Medicine and Rehabilitation, 92(4), 519-530.

Cohen, J. (1988). Statistical Power Analysis for the Behavioral Sciences (2nd edn). Hillsdale, New Jersey: L: Erlbaum.

das Nair, R., Martin, K. J., \& Lincoln, N. B. (2016). Memory Rehabilitation for people with multiple sclerosis. Cochrane Database of Systematic Reviews, 2016(3) CD008754.

das Nair, R., \& Lincoln, N. B. (2012). Evaluation of Rehabilitation of Memory in Neurological Disabilities (ReMiND): A randomized controlled trial. Clinical Rehabilitation. Vol., 26(10), 894-903.

de Joode, E., van Heugten, C., Verhey, F., \& van Boxtel, M. (2010). Efficacy and usability of assistive technology for patients with cognitive deficits: A systematic review. Clinical Rehabilitation, 701-714.

Dewar, B.-K., Kopelman, M., Kapur, N., \& Wilson, B. A. (2014). Assistive technology for memory. In B. O’Neill \& A. Gillespie (Eds.), Assistive Technology for Cognition: A Handbook for Clinicians and Developers (pp. 31-46) Hove: Psychology Press.

Elbourne, D. R., Altman, D. G., Higgins, J. P., Curtin, F., Worthington, H. V., \& Vail, A. (2002). Meta-analyses involving cross-over trials: methodological issues. International Journal of Epidemiology, 31(1), 140-149.

Engel, C., Greim, B., \& Zettl, U. K. (2007). Diagnostics of cognitive dysfunctions in multiple sclerosis. Journal of Neurology, 254(2), II30-II34.

Evans, J. J., Wilson, B. A., \& Emslie, H. (1996). Selecting, administering and interpreting cognitive tests: guidelines for clinicians and therapists. Bury St. Edmunds: Thames Valley Test Company.

Evans, J. J. (2004). Disorders of memory. In L. H. Goldstein \& J. E. McNeil (Eds.), Clinical neuropsychology: A practical guide to assessment and management for clinicians (pp. 143-164) Chichester: John Wiley \& Sons Ltd.

Evans, J. J. (2006). Memory rehabilitation-should we be aiming for restoration or compensation? Journal of Neurology, 253(4), 520-521

Field, A. (2013). Discovering statistics using IBM SPSS statistics. London: Sage.

Fish, J., Manly, T., Emslie, H., Evans, J. J., \& Wilson, B. A. (2008). Compensatory strategies for acquired disorders of memory and planning: Differential effects of a paging system for patients with brain injury of traumatic versus 
cerebrovascular aetiology. Journal of Neurology, Neurosurgery \& Psychiatry, 79(8), 930-935.

Gilchrist, A. C., \& Creed, F. H. (1994). Depression, cognitive impairment and social stress in multiple sclerosis. Journal of Psychosomatic Research, 38(3), 193-201.

Goldberg, D., \& Williams, P. (1988). General Health Questionnaire (GHQ). Swindon, Wiltshire, UK: nfer-Nelson.

Goodwin, R. A. (2016). Evaluation of Neurotext as a memory aid for people with multiple sclerosis (Doctoral dissertation, University of Nottingham).

Goodwin, R., Lincoln, N., das Nair, R., \& Bateman, A. (2017). External memory aids for memory problems in people with multiple sclerosis: A systematic review. Neuropsychological Rehabilitation, 27(8), 1081-1102..

Grima, D., Torrance, G., Francis, G., Rice, G., Rosner, A., \& Lafortune, L. (2000). Cost and health related quality of life consequences of multiple sclerosis. Multiple Sclerosis, 6(2), 91-98.

Hanssen, K. T., Šaltytė Benth, J., Beiske, A. G., Landrø, N. I., \& Hessen, E. (2015). Goal attainment in cognitive rehabilitation in MS patients. Neuropsychological Rehabilitation, 25(1), 137-154.

Hersh, N. A., \& Treadgold, L. G. (1994). Neuropage: The rehabilitation of memory dysfunction by prosthetic memory and cueing. NeuroRehabilitation, 4(3), 187197.

Higgins, J., \& Green, S. (2013). Cochrane handbook for systematic reviews of interventions version 5.1. 0. The Cochrane Collaboration.

Jamieson, M., Cullen, B., McGee-Lennon, M., Brewster, S., \& Evans, J. J. (2014). The efficacy of cognitive prosthetic technology for people with memory impairments: A systematic review and meta-analysis. Neuropsychological Rehabilitation, 24(3-4), 419-444.

Johnson, K. L., Bamer, A. M., Yorkston, K. M., \& Amtmann, D. (2009). Use of cognitive aids and other assistive technology by individuals with multiple sclerosis. Disability and rehabilitation. Assistive technology, 4(1), 1-8.

Kapur, N., Glisky, E. L., \& Wilson, B. A. (2004). Technological memory aids for people with memory deficits. Neuropsychological Rehabilitation, 14(1-2), 4160. 
Khan, F., Pallant, J. F., \& Turner-Stokes, L. (2008). Use of goal attainment scaling in inpatient rehabilitation for persons with multiple sclerosis. Archives of Physical Medicine and Rehabilitation, 89(4), 652-659

Lannin, N., Carr, B., Allaous, J., Mackenzie, B., Falcon, A., \& Tate, R. (2014). A randomized controlled trial of the effectiveness of handheld computers for improving everyday memory functioning in patients with memory impairments after acquired brain injury. Clinical Rehabilitation.

Lincoln, N., Dent, A., Harding, J., Weyman, N., Nicholl, C., Blumhardt, L., \& Playford, E. (2002). Evaluation of cognitive assessment and cognitive intervention for people with multiple sclerosis. Journal of Neurology, Neurosurgery, and Psychiatry, 72(1), 93-98.

Linden, M., Hawley, C., Blackwood, B., Evans, J., Anderson, V., \& O’Rourke, C. (2016). Technological aids for the rehabilitation of memory and executive functioning in children and adolescents with acquired brain injury. Cochrane Database of Systematic Reviews, 2016(7) CD011020.

Martin-Saez, M., Deakins, J., Winson, R., Watson, P., \& Wilson, B. A. (2011). A 10year follow up of a paging service for people with memory and planning problems within a healthcare system: How do recent users differ from the original users? Neuropsychological Rehabilitation, 21(6), 769-783.

O'Brien, A., Chiaravalloti, N., Goverover, Y., \& DeLuca, J. (2008). Evidenced-based cognitive rehabilitation for persons with multiple sclerosis: A review of the literature. Archives of Physical Medicine and Rehabilitation, 89(4), 761-769.

Perneger, T. V. (1998). What's wrong with Bonferroni adjustments. BMJ: British Medical Journal, 316(7139), 1236.

Rao, S. M., Leo, G. J., Ellington, L., Nauertz, T., Bernardin, L., \& Unverzagt, F. (1991). Cognitive dysfunction in multiple sclerosis. II. Impact on employment and social functioning. Neurology, 41(5), 692-696.

Robertson, I. H., Ward, T., Ridgeway, V., \& Nimmo-Smith, I. (1994). The Test of Everyday Attention. Bury St. Edmunds: Thames Valley Test Company.

Rosti-Otajärvi, E. M., \& Hämäläinen, P. I. (2014). Neuropsychological rehabilitation for multiple sclerosis. Cochrane Database of Systematic Reviews, 2014(2) CD009131. 
Sá, M. J. (2008). Psychological aspects of multiple sclerosis. Clinical neurology and neurosurgery, 110(9), 868-877.

Samartzis, L., Gavala, E., Zoukos, Y., Aspiotis, A., \& Thomaides, T. (2014). Perceived cognitive decline in multiple sclerosis impacts quality of life independently of depression. Rehabilitation Research and Practice, 2014.

Smith, G., Del Sala, S., Logie, R. H., \& Maylor, E. A. (2000). Prospective and retrospective memory in normal ageing and dementia: A questionnaire study. Memory, 8(5), 311-321.

Sohlberg, M. M., \& Mateer, C. A. (1989). Introduction to cognitive rehabilitation: Theory and practice. New York: Guilford Press.

Sunderland, A., Harris, J. E., \& Baddeley, A. D. (1983). Do laboratory tests predict everyday memory? A neuropsychological study. Journal of Verbal Learning and Verbal Behavior, 22(3), 341-357.

Sunderland, A., Harris, J. E., \& Gleave, J. (1984). Memory failures in everyday life following severe head injury. Journal of Clinical and Experimental Neuropsychology, 6(2), 127-142.

Svoboda, E., Richards, B., Leach, L., \& Mertens, V. (2012). PDA and smartphone use by individuals with moderate-to-severe memory impairment: Application of a theory-driven training programme. Neuropsychological Rehabilitation, 22(3), 408-427.

Teasell, R., Bayona, N., Marshall, S., Cullen, N., Bayley, M., Chundamala, J., ... Hartridge, C. (2007). A systematic review of the rehabilitation of moderate to severe acquired brain injuries. Brain Injury, 21(2), 107-112.

The EuroQol Group (1990). EuroQol-a new facility for the measurement of healthrelated quality of life. Health Policy, 16(3), 199-208.

Thomas, P. W., Thomas, S., Hillier, C., Galvin, K., \& Baker, R. (2006). Psychological interventions for multiple sclerosis. Cochrane Database of Systematic Reviews, 2006(1) CD004431.

Wessels, R., Dijcks, B., Soede, M., Gelderblom, G., \& De Witte, L. (2003). Non-use of provided assistive technology devices, a literature overview. Technology and Disability, 15(4), 231-238.

Wilson, B. A., Emslie, H., Quirk, K., \& Evans, J. (1999). George: Learning to live independently with NeuroPage®. Rehabilitation Psychology, 44(3), 284. 
Wilson, B., Emslie, H., Quirk, K., \& Evans, J. (2001). Reducing everyday memory and planning problems by means of a paging system: a randomised control crossover study. Journal of Neurology, Neurosurgery \& Psychiatry, 70(4), 477-482.

Wilson, B., Emslie, H., Quirk, K., Evans, J., \& Watson, P. (2005). A randomized control trial to evaluate a paging system for people with traumatic brain injury. Brain Injury, 19(11), 891-894.

Wilson, B., Evans, J. J., Emslie, H., \& Malinek, V. (1997). Evaluation of NeuroPage: a new memory aid. Journal of Neurology, Neurosurgery \& Psychiatry, 63(1), 113-115. 
Table 1. Demographic characteristics of participants.

\begin{tabular}{|c|c|c|c|c|c|c|c|c|}
\hline Demographic characteristic & \multicolumn{4}{|c|}{ Group 1} & \multicolumn{4}{|c|}{ Group 2} \\
\hline Years since diagnosis & 17 & 10.6 & 9.8 & $1-37$ & 21 & 9.7 & 9.4 & $1-33$ \\
\hline
\end{tabular}

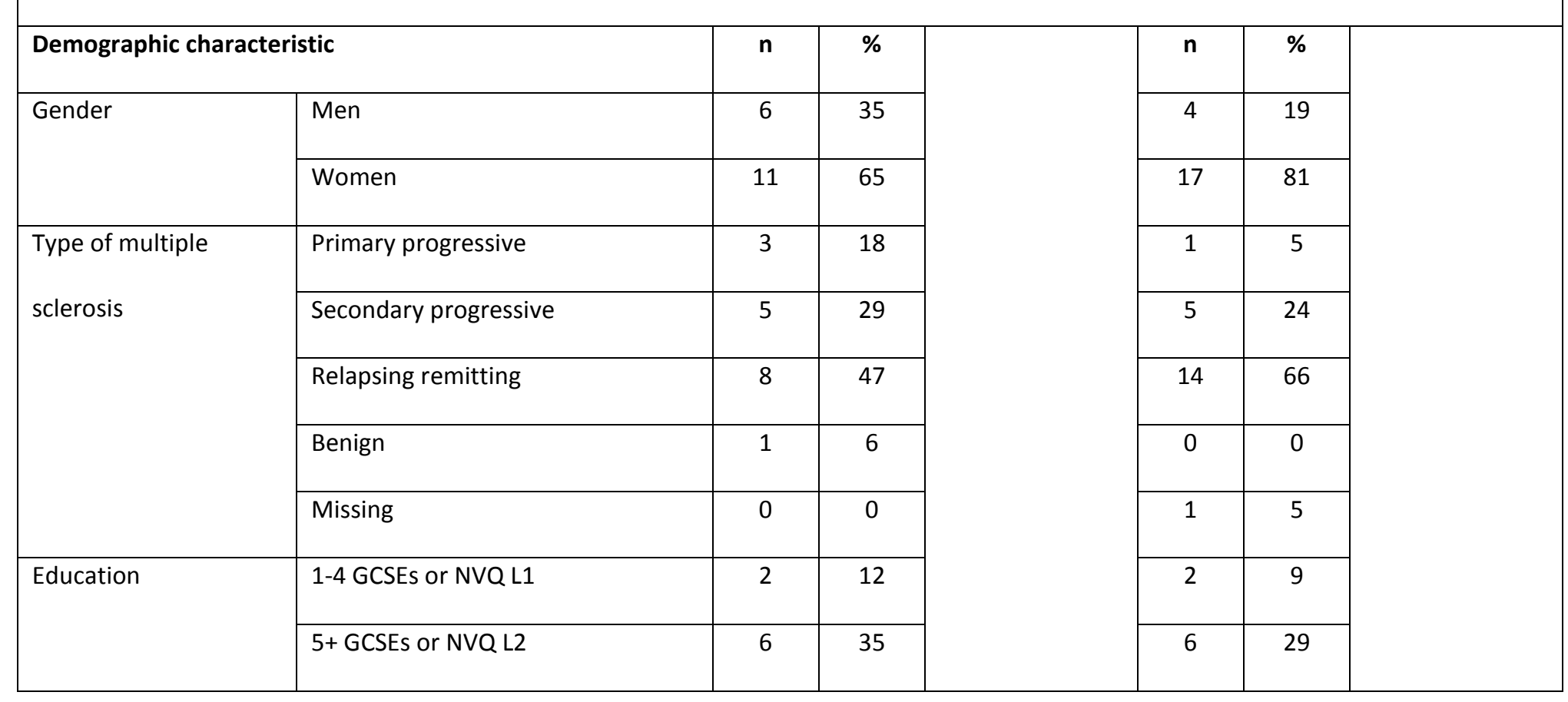




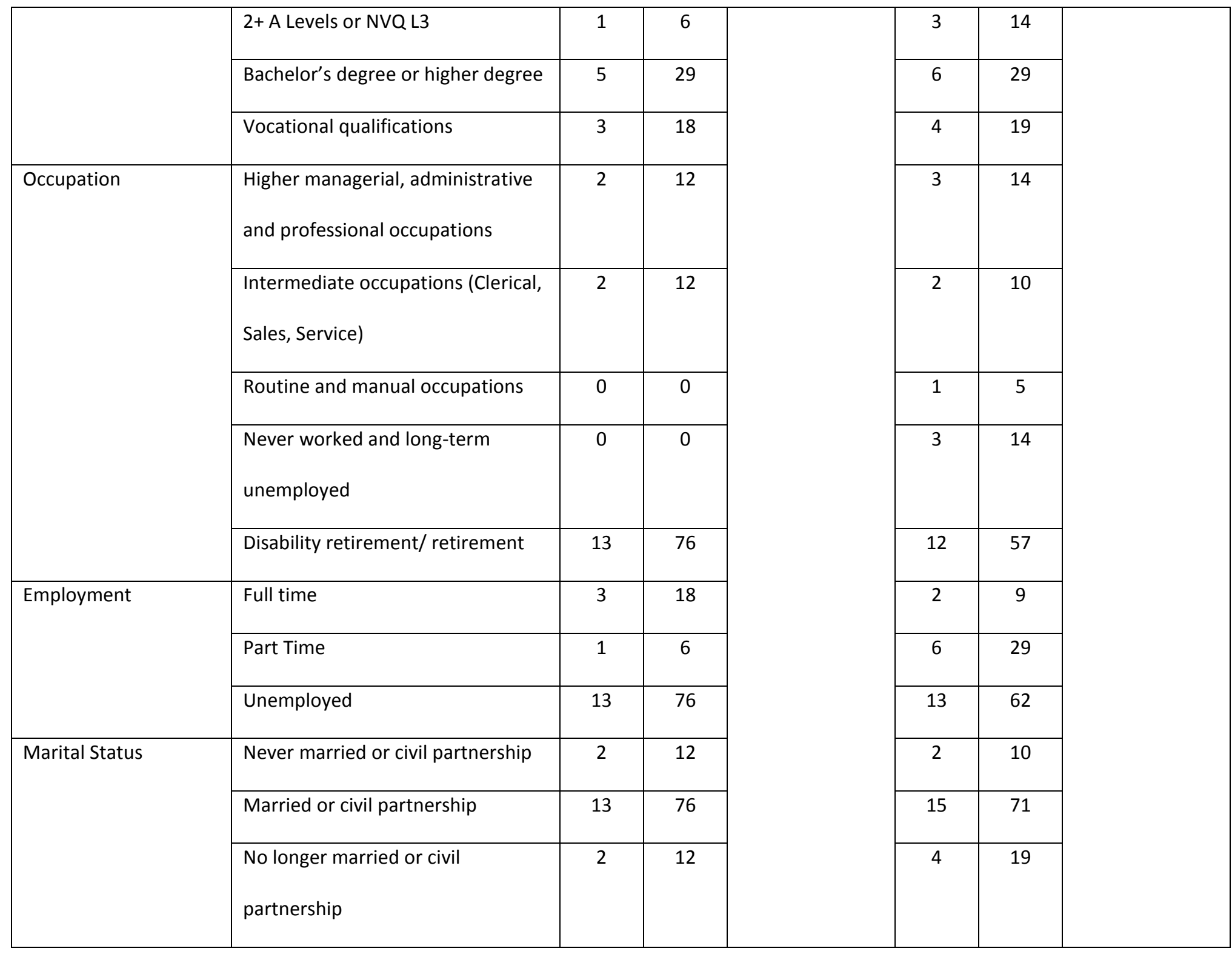


GCSE General Certificate of Secondary Education

NVQ National Vocational Qualifications

A Level Advanced Level 
Table 2. Distribution of scores on baseline measures

\begin{tabular}{|c|c|c|c|c|c|c|c|c|}
\hline & \multicolumn{4}{|c|}{ Group 1} & \multicolumn{4}{|c|}{ Group 2} \\
\hline & $\mathrm{n}$ & Mean & SD & Range & $\mathrm{n}$ & Mean & SD & Range \\
\hline Everyday Memory Questionnaire & 17 & 51.6 & 17.8 & $32-86$ & 21 & 53.3 & 18.2 & $21-99$ \\
\hline \multicolumn{9}{|l|}{ Doors \& People Test Scaled Scores } \\
\hline People & 17 & 7.8 & 3.6 & $1-13$ & 21 & 7.3 & 3.5 & $1-13$ \\
\hline Doors & 17 & 7.3 & 4.3 & $1-14$ & 21 & 6.4 & 2.9 & $1-11$ \\
\hline Shapes & 17 & 9.0 & 5.3 & $0-16$ & 21 & 8.8 & 3.7 & $0-14$ \\
\hline Names & 17 & 7.4 & 4.5 & $0-15$ & 21 & 10.4 & 4.1 & $1-16$ \\
\hline Overall Score & 17 & 7.7 & 4.6 & $0-15$ & 21 & 7.6 & 4.3 & $0-13$ \\
\hline \multicolumn{9}{|l|}{ Hayling \& Brixton Sten scores } \\
\hline Hayling error & 17 & 5.8 & 2.0 & $1-8$ & 21 & 5.6 & 1.8 & $1-8$ \\
\hline Hayling overall & 17 & 5.0 & 1.7 & $1-7$ & 21 & 5.1 & 1.4 & $1-6$ \\
\hline Brixton & 17 & 5.2 & 2.7 & $1-10$ & 21 & 5.1 & 2.3 & $1-9$ \\
\hline \multicolumn{9}{|c|}{ Test of Everyday Attention Age-Scaled scores } \\
\hline Map search 1 & 15 & 7.1 & 3.4 & $0-12$ & 21 & 7.0 & 3.4 & $0-12$ \\
\hline Map search 2 & 15 & 6.9 & 3.0 & $0-11$ & 21 & 6.5 & 3.4 & $0-13$ \\
\hline Elevator counting & 17 & 6.5 & 0.7 & $5-7$ & 21 & 6.9 & 0.4 & $6-7$ \\
\hline
\end{tabular}




\begin{tabular}{|l|l|l|l|l|l|l|l|l|}
\hline Elevator counting with distraction & 17 & 9.2 & 3.0 & $5-13$ & 21 & 10.6 & 2.3 & $6-13$ \\
\hline Visual elevator 1 & 16 & 8.8 & 3.6 & $3-15$ & 20 & 9.9 & 2.4 & $5-14$ \\
\hline Visual elevator 2 & 16 & 7.8 & 4.0 & $0-13$ & 20 & 8.3 & 2.8 & $2-15$ \\
\hline Elevator counting with reversal & 13 & 10.9 & 3.7 & $5-18$ & 19 & 9.6 & 3.7 & $2-15$ \\
\hline Telephone search & 16 & 7.6 & 3.5 & $0-12$ & 21 & 8.1 & 3.4 & $0-15$ \\
\hline Telephone search while counting & 16 & 8.2 & 3.7 & $0-15$ & 21 & 8.6 & 3.6 & $0-15$ \\
\hline Lottery & 17 & 7.8 & 4.1 & $1-13$ & 20 & 9.6 & 3.3 & $4-13$ \\
\hline
\end{tabular}


Table 3. Most frequently requested text messages

\begin{tabular}{|c|c|c|c|c|}
\hline & $\begin{array}{l}\text { Group } 1 \\
\text { NeuroPage then control }\end{array}$ & Percentage of messages & $\begin{array}{l}\text { Group } 2 \\
\text { Control then NeuroPage }\end{array}$ & Percentage of messages \\
\hline \multirow{6}{*}{$\begin{array}{l}\text { NeuroPage } \\
\text { Condition: Requested } \\
\text { content }\end{array}$} & Medication & 36 & Medication & 47 \\
\hline & Toilet & 10 & Today is & 11 \\
\hline & Drink & 8 & Check calendar/diary & 8 \\
\hline & Eat meal & 7 & Charge phone & 6 \\
\hline & Check calendar/diary & 6 & Eat meal & 4 \\
\hline & Today is & 4 & Prepare food & 3 \\
\hline \multirow{4}{*}{$\begin{array}{l}\text { Control Condition: } \\
\text { Requested content }\end{array}$} & Current affairs & 68 & Current affairs & 51 \\
\hline & Sports news & 15 & Specific news & 36 \\
\hline & Specific news & 13 & Sports news & 13 \\
\hline & Quotes & 4 & & \\
\hline
\end{tabular}


Table 4. Comparison of conditions on outcome measures

\begin{tabular}{|c|c|c|c|c|c|c|c|c|c|c|c|c|}
\hline \multirow[t]{2}{*}{ Measure } & \multicolumn{4}{|c|}{ NeuroPage } & \multicolumn{4}{|c|}{ Control } & \multicolumn{4}{|c|}{ Comparison } \\
\hline & $\mathrm{n}$ & Mean & SD & Range & $\mathrm{n}$ & Mean & SD & Range & $\mathrm{t}$ & $\mathrm{df}$ & $p$ & Cohen's d \\
\hline Everyday Memory Questionnaire & 27 & 40.3 & 22.9 & $1-83$ & 29 & 40.7 & 21.3 & $4-90$ & 0.12 & 24 & 0.90 & 0.02 \\
\hline General Health Questionnaire & 24 & 31.9 & 12.6 & $8-61$ & 26 & 39.7 & 16.2 & $21-77$ & -3.83 & 20 & $0.001 *$ & $-0.84 * * *$ \\
\hline AMEDO Part A Coping strategies & 24 & 38.5 & 7.9 & $19-52$ & 25 & 38.5 & 6.7 & $25-51$ & 0.23 & 20 & 0.82 & 0.05 \\
\hline AMEDO Part B1 External Aids & 24 & 14.2 & 2.7 & $9-16$ & 25 & 13.7 & 3.2 & $4-16$ & 1.11 & 20 & 0.28 & 0.24 \\
\hline AMEDO Part B2 Internal Aids & 22 & 11.2 & 3.7 & $4-16$ & 21 & 12.2 & 3.7 & $4-16$ & -1.92 & 17 & 0.07 & -0.45 \\
\hline EQ5D Usual Activities & 24 & 2.0 & 0.4 & $1-3$ & 25 & 2.0 & 0.7 & $1-3$ & 0.33 & 20 & 0.75 & 0.07 \\
\hline EQ5D Pain/ Discomfort & 24 & 2.3 & 0.6 & $1-3$ & 25 & 2.2 & 0.7 & $1-3$ & 0.44 & 20 & 0.67 & 0.10 \\
\hline EQ5D Anxiety/Depression & 24 & 1.6 & 0.6 & $1-3$ & 25 & 1.8 & 0.6 & $1-3$ & -2.17 & 20 & $0.04^{*}$ & -0.47 \\
\hline EQ5D Visual Analogue Scale & 23 & 53.2 & 26.4 & $14-100$ & 24 & 44.5 & 22.5 & $9-92$ & 2.03 & 19 & 0.06 & 0.45 \\
\hline Everyday Memory Questionnaire -Informant & 20 & 35.0 & 19.7 & $0-71$ & 20 & 33.2 & 18.9 & $1-91$ & -1.66 & 16 & 0.12 & -0.40 \\
\hline $\begin{array}{l}\text { Daily Diary } \\
\text { \% target behaviours forgotten }\end{array}$ & 20 & 8.8 & 9.9 & $0-53$ & 20 & 30.0 & 33.9 & $0-100$ & -2.88 & 19 & $0.01^{*}$ & $-0.64 * *$ \\
\hline
\end{tabular}

*significant treatment effect $\mathrm{p}<0.05$ 
** moderate effect size $\mathrm{d}>0.5$

$* * *$ large effect size $\mathrm{d}>0.8$

EMQ Everyday Memory Questionnaire

AMEDO Adaptation to Memory Difficulties Outcome measure

EQ5D EuroQuol 5 Dimensions 
Figure 1. NeuroPage timetable example

Figure 2 Control timetable example

Figure 3. Flow of participants through the trial

Word count: 7288 